\title{
How do elderly individuals build up their forgiveness perception?: histories from three homeless men from Colombia
}

\begin{abstract}
Forgiveness is an aspect that has been widely explored in religion art and recently it has taken a special relevance in health research. Studies about forgiveness are diverse and they are related to topics such as: relationship problems, social violence victims and war victims among others. A question that has been proposed about forgiveness is: How is forgiveness set up in people? The topic becomes more complex once we add contexts such as violence and poverty among others. This article is part of a research based on the life experience of three homeless elderly individuals from Colombia. The first, who was a murderer (S1). The second, a priest (S2), and the third one, a farmer (S3). The data collection techniques were: open interviews, researcher's journal, and a narrative matrix. The results evidenced that forgiveness was not part of parental guidance. Its perception was built up through the interaction with people out of their family group. Moreover, bearing in mind the theoretical classification of forgiveness, it was found that among the units of sense of the three participants, there is a unilateral concept, aiming to take back the emotional wellbeing which was lost for a difficult situation. Also, it was episodic because for the elderly individuals it only has usage in certain circumstances.
\end{abstract}

Volume 2 Issue 4 - 2017

\author{
Paulo Gonzalez,' Martin Suarez,' Rubiela \\ Tapasco,' Elcy Astudillo ${ }^{3}$ \\ School of Social Sciences, Universidad Nacional Abierta y a \\ Distancia, Colombia \\ ${ }^{2} S$ chool of Education, Universidad Nacional Abierta y a \\ Distancia, Colombia \\ ${ }^{3}$ School of Health Sciences, Universidad Libre de Pereira, \\ Colombia
}

Correspondence: Paulo Cesar Gonzalez, School of Social Sciences, Universidad Nacional Abierta y a Distancia, Colombia, Tel 3/37527400,Email paulo.gonzalez@unad.edu.co

Received: August 0I, 2017 | Published: October 24, 2017

Keywords: forgiveness, elderly individuals, homeless, life history

\section{Introduction}

Forgiveness is associated to mental health, physical health and psychological wellbeing ${ }^{1-5}$ due to the liberation of permanent pain caused by intense resentment. It was possible to interpret the particular experiences and individual perceptions based on the data collected. In 1979, Beck suggests the formation of cognitive schemes referred to the world, to others and to itself. Inside that cognitive element it is found the individual concept that every person has. In this way, forgiveness results from a process that is analyzed as a process of adaptation. ${ }^{6}$ In addition, forgiveness has a longevity effect, according to the type of forgiveness that is built. ${ }^{7}$

\section{Procedure}

The history of the three elderly individuals who are part of this research is affected by traumatic and challenging events that built up their concepts about forgiveness and revenge. S1, shares the case of the murder of his father and 4 brothers due to political violence. With this in mind, S1 considers that his decision was taking revenge, confessing the murder of those who killed his family members. The S2, was taken into a boarding school when he was 7 years old. He did not have siblings and mentions that he has always been alone. He passed from the boarding school to a religious career until he became a priest. S3 was given to an aunt when the mother abandoned his father due to physical abuse.

Since the first interaction with the elderly individuals, they revealed the existence of sadness feelings abandonment and complete loneliness that has negatively affected their physical, psychological and social wellbeing. It is assumed that these effects were caused by the challenges they faced throughout their lives. Moreover, they are constantly discriminated for being homeless. It was evidenced a contradiction between the idea of forgiveness and its application. It was also identified the absence of forgiveness references from their family contexts due to the lack of affective interactions and absent relationships with their parents that limit the acquisition of forgiveness as a tool to solve conflicts, reconciliation and the recovering of social bonds.

Nevertheless, apart from the interpersonal relations in nonfamiliar contexts it is developed an idea of forgiveness, as a tool capable of providing them psychological recovering and emotional balance. For S2, forgiveness is built up from his religious training. In this way it is seen as a tool to live in harmony. However for S2 and S3 the application of forgiveness has an ambivalent scheme, because even though they expressed they have forgiven, they blame those experiences, as the consequence for becoming homeless. Moreover, there were found emotional gaps, negative feelings and the absence of closure. These consequences would have been solved through forgiveness and it would have provided emotional tranquility that is necessary to face their current situation in a different way. Forgiveness would have also helped to execute the process of closure which is necessary in these cases.

According to the classification that resulted from other case studies, developed by other authors ${ }^{8-10}$ it was found in the S1 that the concept is merely intra-individual. It means, a unilateral scheme because it understands forgiveness as a tool that is used for himself. It is not expected a reciprocal acceptance, neither aiming to create and interaction with the person who generated the damage. However it is necessary to mention that inside the confession it was revealed and episodic forgiveness. He said: 'If someone does something wrong, I won't forgive him... I never forget that' S1. 
The previous case, describes a situation that reflects a contradiction between the theoretical concept of forgiveness and its application, revealing internal conflicts with a lack of closure of problematic experiences in their lives. These internal conflicts require attention due to these negative feelings. Another possible consequence is that there was a late application of forgiveness because it did not appear in the early experience with immediate family but from the experience acquired with people different to his family, with a different mental scheme. These people have a different interpretation of interpersonal relationships, being able to create cognitive lapses or distortions related to the topic. ${ }^{11}$

In addition, S3 evidences an episodic forgiveness. It means the one that is applied to certain circumstances. S3 expressed in his own words: 'Forgiveness gives you a sense of relief that is why I have forgiven some things but I have not forgiven others' S3. It is possible to highlight that even though he expressed that he has forgiven, what was the most difficult situation of his life that also caused his homeless condition, there were found in his confessions, negative expressions towards those people that damaged him. It also points out his own ambivalence when there is not a resolution between dispositional forgiveness and emotional forgiveness. ${ }^{5}$

On the other hand, S2, who has the concept of forgiveness influenced by his religious career, interprets it as a tool: 'Forgiveness works to unite, to calm down, in order to achieve tranquility in yourself' S2. His forgiveness concept is unilateral, and refers to the search for a balance and his own emotional wellbeing. He also expresses that this decision, cannot be affected by an external behavior. S2, also provides a more meaningful use to forgiveness than the other participants, when he expresses its importance in life: 'All the importance, the highest importance, because God, gave us an example of forgiveness and love to our peers' S2. This experience has been analyzed in different studies, that point out, the association between forgiveness, spirituality and health. ${ }^{8,12}$

\section{Discussion}

The findings of this study, can evidence that forgiveness is a personal process that presents serious challenges when defining it and recognizing it. In this process, were identified social aspects such as: culture and religion ${ }^{13,14}$ personal grateful experiences, challenging situations, individual aspects such as the personality, the wellbeing feeling and the act of facing difficulties. ${ }^{13,15}$ Analyzing the concept of forgiveness of the three participants and comparing it with the theoretical classification that was provided, it is defined that participants S1 and S3 possess a more instrumental concept, bearing in mind that forgiveness is a way to achieve a benefit through social acceptance or as a tool for negotiation. ${ }^{15-17}$ The concept of forgiveness, is also associated to the necessity of recovering their emotional and psychological wellbeing, that was lost due to the challenges the participants faced. It seems like they also do it with no expectations from the side of the aggressors, especially when it is not evidenced a strong previous relationship with them. ${ }^{1,11,18}$ This is considered a concept of episodic forgiveness, because it is situational, which means useful for some circumstances but not for others. Specially, those situations related to the experiences that according to them generated the fact of becoming homeless people. For S2, forgiveness is part of his formation and religious conviction, because it is a generalized concept for all the conflictive experiences, and in several studies, it is evidenced the relation between forgiveness and health and the important role that religion plays in it. ${ }^{12,19}$ The difficulties that were mentioned, were also a result of violent circumstances that have characterized the recent Colombian history, that have promoted people's distrust towards the use of forgiveness and also the demonization that has been mediated by cultural aspects. ${ }^{20-24}$ There is a lack of studies that evidence the application of forgiveness by homeless elderly men with different backgrounds who at the end of their lifes face this difficult situation.

\section{Acknowledgements}

None.

\section{Conflict of interest}

Authors declare that there are no conflicts of interest.

\section{References}

1. Pell AFL, Kasanzew A, Fernández MS. Los efectos psicoterapéuticos de estimular la connotación positiva en el incremento del perdón. Av en Psicol Latinoam. 2008;26(2):211-226.

2. Karremans JC, Van LPM, Ouwerkerk JW, et al. When forgiving enhances psychological well-being: the role of interpersonal commitment. J Pers Soc Psychol. 2003;84(5):1011-1126.

3. Whited MC, Wheat AL, Larkin KT. The influence of forgiveness and apology on cardiovascular reactivity and recovery in response to mental stress. J Behav Med. 2010;33(4):293-304.

4. Friedberg JP, Suchday S, Shelov DV. The impact of forgiveness on cardiovascular reactivity and recovery. Int $J$ Psychophysiol. 2007;65(2):87-94.

5. Worthington EL, Witvliet CVO, Pietrini P, et al. Forgiveness, health, and well-being: A review of evidence for emotional versus decisional forgiveness, dispositional forgivingness, and reduced un forgiveness. $J$ Behav Med. 2007;30(4):291-302.

6. McCullough ME, Kurzban R, Tabak B. Cognitive systems for revenge and forgiveness. Behav Brain Sci. 2013;36(1):1-15.

7. Toussaint LL, Owen AD, Cheadle A. Forgive to live: Forgiveness, health and longevity. J Behav Med. 2012;35(4):375-386.

8. Cullough MEL. Promoting forgiveness: A comparison of two brief psycho educational group interventions with a list control. Couns Values. 1995;40(1):55-68.

9. McCullough ME, Rachal KC, Worthington EL. Interpersonal Forgiving in Close Relationships. J Pers Soc Psychol [Internet]. 1997;73(2):321-336.

10. Mullet E, Girard M, Bakhshi P. Conceptualizations of Forgiveness. Eur Psychol. 2004;9(2):78-86.

11. Cioni PF. Forgiveness, cognitive restructuring and object transformation. J Relig Health. 2007;46(3):385-397.

12. Lutjen LJ, Silton NR, Flannelly KJ. Religion, Forgiveness, Hostility and Health: A Structural Equation Analysis. $J$ Relig Health. 2012;51(2):468-478.

13. Ballester S, Chatri F, Sastre MTM, et al. Forgiveness-related motives: A structural and cross-cultural approach. Soc Sci Inf. 2011;50(2):178-200.

14. Paz R, Mullet E. Forgiveness : A China-Western Europe Comparison Forgiveness: A China - Western Europe Comparison. J Psychol. 2012;142(2):147-157.

15. Maltby J, Day L, Barber L. Forgiveness and mental health variables: Interpreting the relationship using an adaptational-continuum model of personality and coping. Pers Individ Dif. 2004;37(8):1629-1641. 
16. Leunissen JM, Cremer DD, Reinders FCP. An instrumental perspective on apologizing in bargaining: The importance of forgiveness to apologize. J Econ Psychol. 2012;33(1):215-222.

17. Fehr R. The forgiving Organization: a Multilevel Model of Forgiveness At Work. Academy of Management Review. 2012;37(4):664-688.

18. Echeburúa E. El valor psicológico del perdón en las víctimas y en los ofensores. Eguzkilore. 2013;27:65-72.

19. Vitz PC, Meade JM. Self-forgiveness in Psychology and Psychotherapy: A Critique. J Relig Health. 2011;50(2):248-263.

20. López EA. Perdonar sí, olvidar no una aproximación a la reconciliación en Colombia desde los sentimientos morales. Univ Philos. 2013;30(61):85-96.
21. López LW, Marín CP, León MCM, et al. Colombian lay people's willingness to forgive different actors of the armed conflict: Results from a pilot study. Psicologica. 2012;33:655-663.

22. Cortés Á, Torres A, López LW, et al. Comprensiones sobre el perdón y la reconciliación en el contexto del conflicto armado colombiano. Psychosoc Interv. 2014;22(2):135-143.

23. Ballester S, Chatri F, Sastre MTM, et al. Forgiveness-related motives: A structural and cross-cultural approach. Soc Sci Inf. 2011;50(2):178-200.

24. Recine AG, Werner JS, Recine L. Concept analysis of forgiveness with a multi-cultural emphasis. J Adv Nurs. 2007;59(3):308-316. 